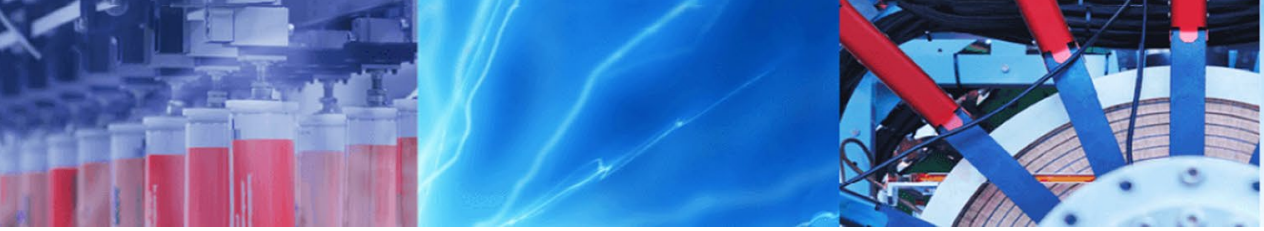

Research Article

\title{
Comparative study of G0289 and 5-bromo-4-formylguaiacol using DFT and MD calculations
}

\author{
Radia Mahboub
}

Received: 21 March 2020 / Accepted: 15 May 2020 / Published online: 23 May 2020

(c) Springer Nature Switzerland AG 2020

\begin{abstract}
We investigated the reactivity of the Schiff base GO289 2, and 5-bromo-4-formylguaiacol 1 by performing quantum chemical calculations using the density functional theory method. First, we employed this method to predict the reliable orbital molecular energies. Next, we calculated the quantum chemical parameters. Electrophilicity index increases with the various electrodificitary sites of GO289 2. This one is greater than this of 5-bromo-4-formylguaiacol 1. The calculated data confirm that the fraction of electrons for GO289 2 is large. We have also evaluated the conformations of these molecules in solution using the molecular dynamics simulation. The calculations confirm that the GO289 2 has a spatial conformation state. Molecular dynamic simulations give us very good results in the prediction of reactivity and inhibition effect. Our theoretical results complete very well the experimental data.
\end{abstract}

Keywords GO289. Guaiacol derivatives · Density functional theory · Molecular dynamics simulation

\section{Introduction}

Guaiacol compounds are extensively used in different area. Bromoguaiacol derivatives are precursors of lignin with high biological activities such as, antioxidant $[1,2]$ and cytokinin-like [3, 4]. Many authors have prepared the 4-bromoguaiacol from guaiacol [5-9]. Other reactions have been carried out on guaiacol, in particular deoxygenation. Several experimental and theoretical studies have been carried out on the deoxygenation of guaiacol [10-15]. Nowadays, authors have investigated to studying the conformations of the phenolic hydroxyl and methoxy groups in guaiacol using $\mathrm{Ab}$ Initio calculation methods [16].

Guaiacol was also studied theoretically with the density functional theory (DFT). This study reveals important conversion to main intermediates such as phenol, anisole and catechol [17]. Recently, Oshima et al. have converted arylhydrazide $\mathbf{A}$ to amino triazole $\mathbf{B}$ using closing reaction with hydrazine followed by alkylation. Then, the condensation reaction between triazole $\mathbf{B}$ and 5-bromo-4-formyl2-methoxyphenol 1 furnished the Schiff base compound: GO289 2 (Fig. 1) [18].

In this work, we compared the structure activity relationship of GO289 2 and 5-bromo-4-formylguaiacol 1 using the quantum chemical methods (DFT). We have also evaluated the conformations of these molecules using the molecular dynamics simulation in solution. Next, we compared our calculated results.

\section{Methodology}

\subsection{Quantum chemical calculations}

The molecular quantum optimisation calculations are performed by density functional theory DFT B3LYP method using 6-31G basis set implemented in Gaussian

Radia Mahboub, radiamahboub@yahoo.com | 'Department of Chemistry, Faculty of Sciences, University of Tlemcen, B.P. 119, 13000 Tlemcen, Algeria. 


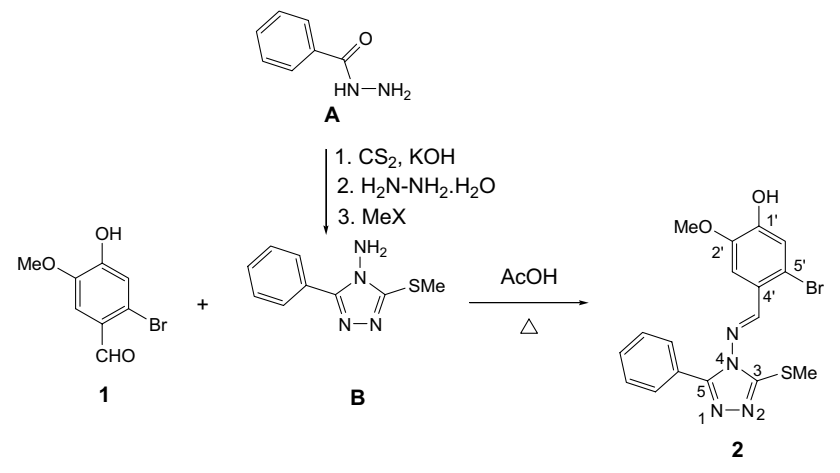

Fig. 1 Synthesis of (E)-5-Bromo-2-methoxy-4-(((3-(methylthio)-5phenyl-4H-1,2,4-triazol-4-yl)imino)methyl)phenol 2 [18]

$03 \mathrm{~W}$ programme [19-22]. The following quantum chemical results are considered: total energy $(E t)$, ionisation potential (IP), energy of the highest occupied molecular orbital $\left(\mathrm{E}_{\mathrm{HOMO}}\right)$, energy of the lowest unoccupied molecular orbital $\left(\mathrm{E}_{\mathrm{LUMO}}\right)$, energy gap $\left(\mathrm{EG}=\mathrm{E}_{\mathrm{LUMO}}-\mathrm{E}_{\mathrm{HOMO}}\right)$, dipole moment $(\mu)$, chemical hardness $(\eta)$, Mulliken electronegativity $\left(\chi=-\left(E_{\text {LUMO }}+E_{\text {HOMO }}\right) / 2\right)$, electrophilicity index $\left(\omega=\chi^{2} / 2 \eta\right)$, and the fraction of electrons $(\Delta N)$.

\subsection{Molecular dynamics (MD) simulation}

All MD simulations were performed with the AMBER force field using Polak-Ribiere conjugate gradient algorithm with a gradient of $0.01 \mathrm{kcal} / \mathrm{mol}$ (RMS). In vacuum, the system was simulated using Molecular Dynamics with 0.0001 ps step. Temperature was kept constant at $300 \mathrm{~K}$. The starting temperature was taken at $100 \mathrm{~K}$ and the step at $20 \mathrm{~K}$. In water simulations, the system was placed in a box $(20 \times 20 \times 20 \AA)$ containing one molecule of studied compound and 240 water molecules and cutoff $4 \AA$ A. Optimisation of the molecule was realised in periodic boundary conditions (PBC). The compounds were solvated by added water molecules. The systems were first energy minimised steps with the conjugate gradient algorithm. Then, the position-restrained MD simulation was run $0.5 \mathrm{ps}$.

\section{Results and discussion}

To our knowledge, no paper has been made to study the comparative structure-activity relationship of the following compounds: 5-bromo-4-formyl-guaiacol 1 and GO289 2 using the DFT B3LYP method and molecular dynamics simulation.
Table 1 Quantum chemical parameters for: 5-bromo-4-formyl2-methoxyphenol 1 and GO289 2 with DFT B3LYP method

\begin{tabular}{llll}
\hline Entry & Parameter & $\begin{array}{l}\text { 5-bromo-4-formyl- } \\
\text { guaiacol 1 }\end{array}$ & GO289 2 \\
\hline 1 & $\mathrm{E}_{t}(\mathrm{eV})$ & $-84,517.906$ & $-108,721.636$ \\
2 & $\mu(\mathrm{D})$ & 3.727 & 5.107 \\
3 & $\mathrm{IP}(\mathrm{eV})$ & 6.410 & 6.013 \\
4 & $\mathrm{HOMO}(\mathrm{eV})$ & -6.410 & -6.013 \\
5 & $\mathrm{LUMO}(\mathrm{eV})$ & -1.970 & -2.122 \\
6 & $\mathrm{EG}(\mathrm{eV})$ & 4.440 & 3.891 \\
7 & $\eta(\mathrm{eV})$ & 2.220 & 1.946 \\
8 & $\sigma(\mathrm{eV}-1)$ & 0.450 & 0.514 \\
9 & $\chi(\mathrm{eV})$ & 4.190 & 4.067 \\
10 & $\omega(\mathrm{eV})$ & $\mathbf{3 . 9 5 4}$ & $\mathbf{4 . 2 5 2}$ \\
11 & $\Delta N_{(110)}$ & 0.142 & $\mathbf{0 . 1 9 4}$ \\
\hline
\end{tabular}

\subsection{Quantum chemical parameters}

In this paper our objective is to study the structure-activity relationship of the GO289 2 compound then to make a comparative study of the reactivity of 5-bromo-4-formyl2-methoxyphenol 1 using the DFT method. From the density functional theory method, we have evaluated: (1) molecular orbital (HOMO and LUMO), (2) chemical hardness $(\eta),(3)$ electrophilicity index $(\omega)$ and $(4)$ the fraction of electrons $\Delta N$.

The energy gap between the HOMO and LUMO describes an important stability factor [23-25]. Large gap involves high stability which leads weak chemical reactivity. However, small gap implies low stability indicating high chemical reactivity. The chemical hardness is the combination of both the chemical reactivity and the stability of a molecule.

The calculated hardness $(\eta)$ indicates that the value of 5-bromoguaiacol $\mathbf{1}$ is greater than that of GO289 2 (Table 1, entry 7, 2: 1.946; 1: 2.220). According to the data in Table 1, there is a relationship between the IP values of reactant/substrate structures and the imine forming reaction. GO289 2 has all ring atoms hybridised sp ${ }^{2}$, and its six $\pi$-electrons are delocalized between triazole and phenyl rings via the imine bond. 5 -Bromoguaiacol $\mathbf{1}$ is considered as electrophile due to the formyl group. Consequently, we conclude that GO289 2 is more reactive if compared to 5-bromoguaiacol 1. In the case of GO289 2, the obtained gap value is lesser than that of 5 -bromoguaiacol 1. Therefore, its chemical reactivity is high if compared to compound 1. 
In 5-bromoguaiacol 1, the activating groups: $\mathrm{OH}, \mathrm{OMe}$ and $\mathrm{Br}$ are necessaries for the stabilization of the aromatic ring by resonance donor effect $(M+)$ (donating electrons to the system). The electron density of these groups is distributed into the aromatic ring. Therefore, the electron deficiency is located on formyl group precisely on carbon atom.

The formyl site attack is greatly fovorized because the steric hindrance between electrophile $\mathbf{1}$ and nucleophile $\mathbf{B}$ does not exist. Therefore, the condensation reaction between triazole $\mathbf{B}$ and 5-bromophenol $\mathbf{1}$ gives the resulted product GO289 2. Scheme 1 reveals a consistent reactivity where electron-rich nitrogen amine $\mathbf{B}$ attacks the electrophile 1 . So, the best interaction HOMO-LUMO would preferentially occur. Our theoretical results complete very well the experimental data of literature [18].

\subsection{Global reactivity descriptors}

We have calculated the electrophilicity index $(\omega)$ from the Mulliken electronegativity $(\chi)$ and the chemical hardness (n). Maynard et al. [26] have demonstrated that this electrophilicity index provide a relationship of an electrophile and the electrophilic power of the inhibitor. In the present study, $\omega$ defined the electrophile character in the condensation reaction. The calculated data show very well that the electrophilicity index increases with withdrawing effect on formyl group in the electrophile 1 (Table 1, entry 10).

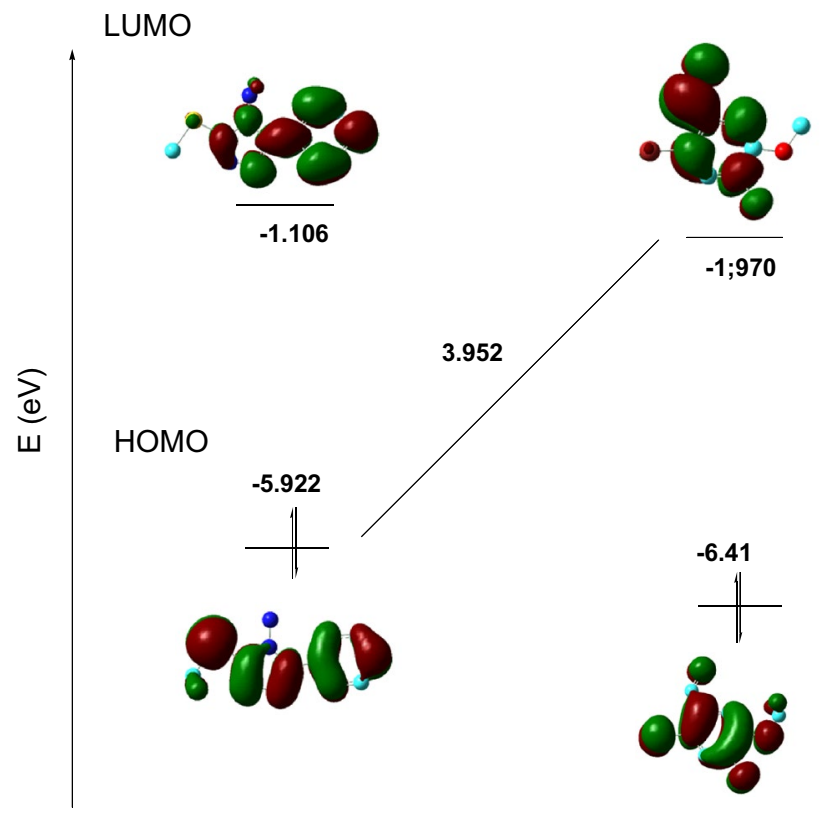

Scheme 1 Frontier molecular orbitals. Triazole B and 5-bromophenol 1. Hydrogens are omitted for clarity
By analogy to electrophilicity index describe by Maynard, the electrophilicity index $(\omega)$ was also defined by Parr et al. as a descriptor to quantify the global electrophilic power of a molecule [27]. Here, the global electrophilic power of GO289 2 is specially localized on imine group and substituted phenol. The electrophilicity index raises with the various electrodificitary sites of this molecule. As a consequence, $\omega$ is more important for $\mathrm{GO} 289$ $\mathbf{2}$ than 5-bromoguaiacol $\mathbf{1}$.

Pearson has reported that the fraction of electrons $\Delta N$ transferred between inhibitor molecules and the metal surface can be estimated according to the following equation [28]:

$\Delta N=\frac{\left(\chi_{\text {met }}-\chi_{\text {inh }}\right)}{2\left(\eta_{\text {inh }}+\eta_{\text {met }}\right)}$

Kokalj has reported that the use of metal work function $\phi \mathrm{Fe}_{(110)}=4.82 \mathrm{eV}$ rather than $\chi_{\mathrm{Fe}}$ is more suitable for an adsorbate-metal surface interaction [29]. Authors have preferred $\mathrm{Fe}_{(110)}$ because it has a packed surface and high stability [30]. Thus, using it in the place of $\chi_{\mathrm{Fe}}$ and putting $\eta_{\mathrm{Fe}}=0$, the above Eq. (1) becomes:

$\Delta N=\frac{\left(\phi_{\mathrm{Fe}_{(110)}}-\chi_{\mathrm{inh}}\right)}{2 \eta_{\mathrm{inh}}}$

From Table 1, we note that $\Delta N$ is great for GO289 2 because the molecular system is highly unsaturated, and contains three resonance-stabilized aromatic rings. Moreover, hydroxyl group and bromine atom are an electron donor types that can provide their charges to the imine bond through the aromatic ring. As a result, they are increasing its nucleophilic effect. 5-Bromoguaiacol 1 has only a withdrawing effect in the formyl group (Fig. 2). As consequence, we can order the fraction of electron as follows: $\mathbf{2}>\mathbf{1}$.

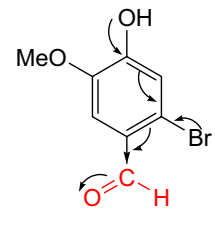

1

Withdrawing effect $\left(\mathrm{I}^{-}\right)$ of formyl group

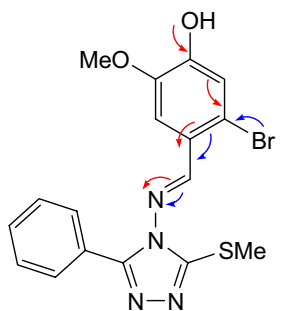

GO289 2

Donnor mesomeric effects $\left(M^{+}\right)$ of $\mathrm{OH}$ and $\mathrm{Br}$
Fig. 2 Electronic effects for 5-bromo-4-formylguaiacol 1 and GO289 2 
The fraction of electrons $\Delta N$ increases when:

(i) The nucleophilicity increases with non-binding doublets, charge and polarizability.

(ii) The molecular system is highly unsaturated and stabilized by resonance.

(iii) The aromatic ring is substituted by mesomer donor groups $\left(\mathrm{M}^{+}\right) \mathrm{OH}$ and $\mathrm{Br}$.

\subsection{Mulliken charges}

For GO289 2, we note that the HOMO is located over two rich aromatic rings ( $\mathrm{Bz}$ and triazole), sulfur and nitrogen atoms (Fig. $3 \mathrm{a}_{2}$ ). In LUMO orbital, we observe that the charge density $(C D)$ is situated principally around imine bond and slightly on the third aromatic ring (Fig. $3 \mathrm{~b}_{2}, \mathrm{c}_{2}$ ). In HOMO, CD is essentially delocalised over the two rings (Bz and triazole) through the imine bond. These situations seem be the same in the context of 5-bromo-4-formylguaiacol 1 (Fig. $3 / a_{1}, b_{1}, c_{1}$ ). So, the reactivity has been estimated on the aromatic moiety and on the electronegative atoms of these compounds. The Mulliken charges are given in Table 2.

We conclude that the inhibition is more efficient if the electron transfer from the target molecule to the Fe metal is large. Therefore, GO289 2 is an inhibitor of choice. This compound can better reduce the corrosion of iron. This result indicates that inhibition depends on the structure of the molecule. Here, inhibition and reactivity increase with the presence of mesomer donor groups and highly unsaturated and stabilized aromatic systems. We can conclude that the fraction of electrons $\Delta N$ and the electrophilicity index $\omega$ vary in same direction for the two compounds $\mathbf{1}$ and $\mathbf{2}$. For compound $\mathbf{2}$ the fraction of electrons $\Delta N$ is higher than compound $\mathbf{1}$ because of the electrophile character of this compound.

\subsection{Molecular electrostatic potential}

Molecular electrostatic potential (MEP) provides valuable information concerning the polarity of the compounds $[31,32]$. The electrostatic potential (ESP) contour of compounds $\mathbf{1}$ and $\mathbf{2}$ illustrates the two-dimensional charge distribution of these molecules computed at the 0.004 a. u. isovalue diagrams. The electrostatic potential representation clearly shows that the $\sigma$-withdrawing properties of the oxygen on the methoxy, hydroxyl and formyl groups reduce the $\pi$-donating and deactivate the ring. In 5-bromo-4-formylguaiacol 1, formyl has a large charge compared to $\mathrm{GO} 289$ 2. Therefore, this molecule becomes polar due to the presence of the triazole group and the imine bond. Polarizability is increased because of the presence of nitrogen and sulfur atoms. Therefore, these atoms reveal the molecular interactions between molecules. The green colour region depicts the neutral electrostatic region. The red colour regions in ESP indicate the positive potential region which is the favourable site for nucleophilic attack.

The negative regions are associated to: oxygen atoms in methoxy, hydroxyl and formyl groups, and nitrogen atoms in triazole group and imine bond (Fig. 4). The oxygen atom in hydroxyl with electrostatic potentials ranging from -4 to $-2 \times 10^{-2}$ a. $u$ has be unchanged in both compounds but bromine atom decrease in compound $\mathbf{2}$ rather $\mathbf{1}$. The electrostatic potentials of nitrogen atoms in triazole group and imine bond vary from -4 to -0.8 and -4 to $-2 \times 10^{-2}$ a.u.

\subsection{Molecular dynamic simulation}

Molecular dynamics method has been widely used to understand the interaction and adsorption behavior of an inhibitor on the metal surface [31-34].

In the present study, we have used this efficient method to investigate the adsorption behavior of GO289 2 and compound 1 . The binding energy $\left(E_{\text {bind }}\right)$ was used to estimate the adsorption intensity of the inhibitor molecules on the metal surface when the simulation system reaches thermal and energetic equilibrium. The interaction and binding energies in solution simulation system can be calculated by Eq. 3 [35]

$E_{\text {bind }}=-E_{\text {int }}=-\left(E_{\text {Total }}-\left(E_{\text {Solvent }}+E_{\text {Molecule }}\right)\right)$

where $\mathrm{E}_{\text {Total }}$ represents the energy of the entire system, $E_{\text {Solvent }}$ represents the entire energy of water solution and $\mathrm{E}_{\text {Molecule }}$ represents the whole energy of target molecule.

To simulate the interaction behaviour of the GO289 2 and compound $\mathbf{1}$, we have proceeded as follow:

(i) First, the 3-D periodic box (PB) $(20 \times 20 \times 20 \AA)$ containing 240 water molecules was equilibrated at $300 \mathrm{~K}$ using MD simulations. So, the resulted total energy of $\mathrm{PB}$ is $\mathrm{E}_{\mathrm{TH} 2 \mathrm{O}}=-2387.480 \mathrm{kcal} / \mathrm{mol}$.

(ii) Then one molecule of each studied molecule ( 2 and 1) was added to 3-D PB containing 240 water molecules and the system was equilibrated at $300 \mathrm{~K}$ using MD simulations. 


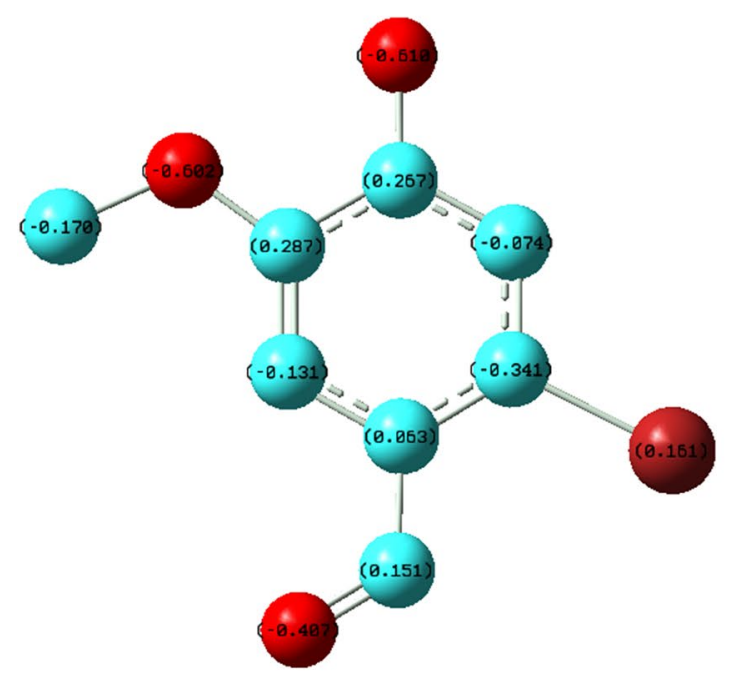

(a1)

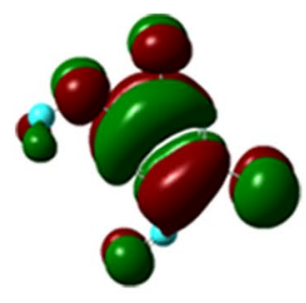

(b1)

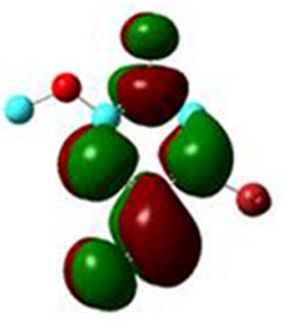

(c1)

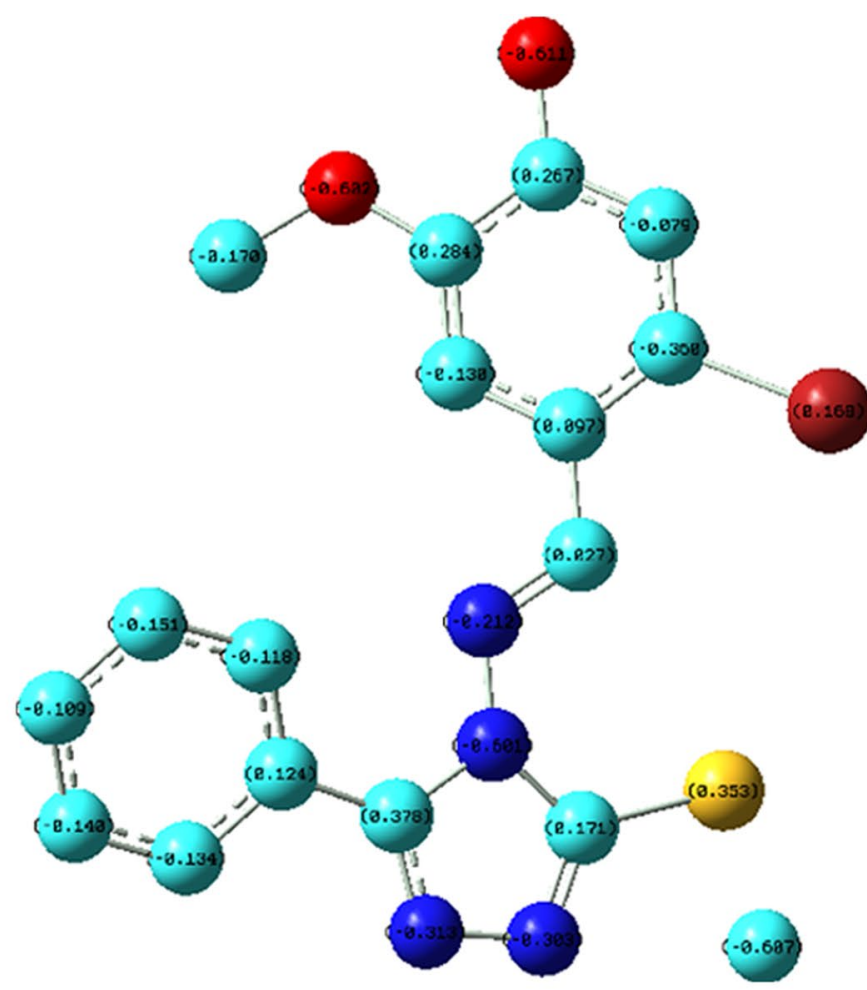

(a2)

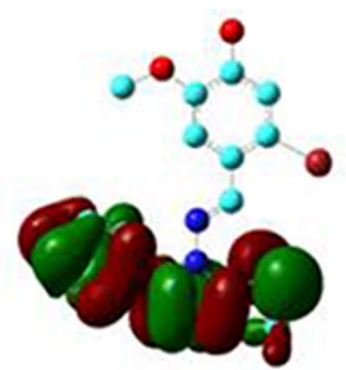

(b2)

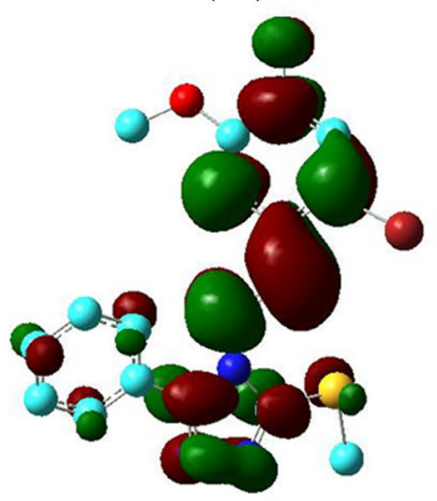

(c2)

Fig. 3 Quantum parameters of a) 5-bromo-4-formylguaiacol 1 and b) GO289 2: a Mulliken charges, b HOMO and c LUMO by the DFT method. Hydrogens are omitted for clarity 
Table 2 Mulliken charges for 5-bromo-4-formylguaiacol 1 and GO289 2 using the DFT method

\begin{tabular}{ll}
\hline Compound & Type/Charge \\
\hline GO289 2 & $\mathrm{N}_{1}-0.313, \mathrm{~N}_{2}-0.303, \mathrm{C}_{3} 0.171, \mathrm{~N}_{4}-0.601, \mathrm{C}_{5}$ \\
& $0.378, \mathrm{~S} 0.353, \mathrm{C}_{\mathrm{Me}} \mathrm{s}-0.607, \mathrm{~N}_{\text {imino }}-0.212$, \\
& $\mathrm{CH} 0.027, \mathrm{H} \underline{\mathrm{O}}-0.611, \mathrm{Me} \underline{\mathrm{O}}-0.602, \mathrm{C}_{\mathrm{ME}}$ \\
& $-0.170, \mathrm{Br} 0.168, \mathrm{C}_{1^{\prime}} 0.267, \mathrm{C}_{2^{\prime}} 0.284, \mathrm{C}_{3^{\prime}}$ \\
& $-0.138, \mathrm{C}_{4^{\prime}} 0.097, \mathrm{C}_{5^{\prime}}-0.360, \mathrm{C}_{6^{\prime}}-0.079$ \\
5-bromo-4-formyl- & $\mathrm{H} \underline{\mathrm{O}}-0.61, \mathrm{Me} \underline{\mathrm{O}}-0.602, \mathrm{C}=\underline{\mathrm{O}}-0.407, \mathrm{Br}$ \\
guaiacol 1 & $0.168, \mathrm{C}_{1} 0.267, \mathrm{C}_{2} 0.287, \mathrm{C}_{3}-0.131, \mathrm{C}_{4}$ \\
& $0.063, \mathrm{C}_{5}-0.341, \mathrm{C}_{6}-0.074, \mathrm{CH} 0.151, \mathrm{C}_{\mathrm{ME}}$ \\
& -0.170 \\
\hline
\end{tabular}

We used the MD simulation to predict configuration of the inhibitory molecule adsorbed at the metal interface when equilibrium is reached. In the present work, we have determined the total energy of each molecule in the gas state, the total energy of the system and the energy of interaction. The obtained values of the energies are summarized in Table 3 and the best configurations in the solution are shown in Fig. $5 \mathrm{a}, \mathrm{b}$.

From Fig. 5a, we observe that the molecule 1 have a planar structure and can move to the Fe surface as parallel as possible. The GO289 2 can be adsorbed on the metal surface with a folded configuration (Fig. 5b). We think that spatial and non-parallel adsorption is due to type interaction between inhibitory GO289 2 and metal. The Schiff base $\mathbf{2}$ has a sufficient amount of N, O, Br and S donor heteroatoms as well as $\pi$ electrons in its structure which provide enough electrons to the vacant orbital metal.
Table 3 Calculated MD parameters for 5-bromo-4-formylguaiacol 1 and GO289 2

\begin{tabular}{llcr}
\hline Entry & Property & $\begin{array}{l}\text { 5-bromo-4-for- } \\
\text { mylguaiacol 1 }\end{array}$ & \multicolumn{1}{c}{ GO289 2 } \\
\hline 1 & $E t_{\text {molecule gas }}(\mathrm{kcal} / \mathrm{mol})$ & 37.428 & 84.027 \\
2 & $E t_{\text {Total }}(\mathrm{kcal} / \mathrm{mol})$ & -2393.550 & -2327.710 \\
3 & $\mathrm{E}_{\text {int }}(\mathrm{kcal} / \mathrm{mol})$ & -43.498 & -14.257 \\
\hline
\end{tabular}

From Table 3, we note that the calculated interaction energy values of the adsorption systems at $300 \mathrm{~K}$ are -43.498 and $-14.257 \mathrm{kcal} / \mathrm{mol}$ for 1 and $\mathbf{2}$, respectively. These high values of negative energy suggest that the adsorption process is spontaneous in nature. We can suggest from this interaction energy value, that molecule $\mathbf{2}$ gives complex structure with water molecules and adsorb on the iron surface more spontaneously than that of $\mathbf{1}$. As a consequence, we classify these molecules in the following order: $2>1$. In Fig. 6, we propose the complex structure and adsorption sites of GO289 2 specie in water on the iron surface.

From literature, we note that corrosion takes place in acidic medium when using Schiff base, benzotriazole, quinazolinone and pyrimidinone because of the basic character of these compounds [28, 29, 34, 36]. Our results are in good agreement with those obtained from literature. We conclude that GO289 2 has the lower chemical hardness $\eta$ and lower binding energy $E_{\text {Bind }}$ which are significant of high reactivity.
Fig. 4 ESP 2D representation of: a 5-bromo-4-formylguaiacol 1 and b GO289 2. Hydrogens are omitted for clarity

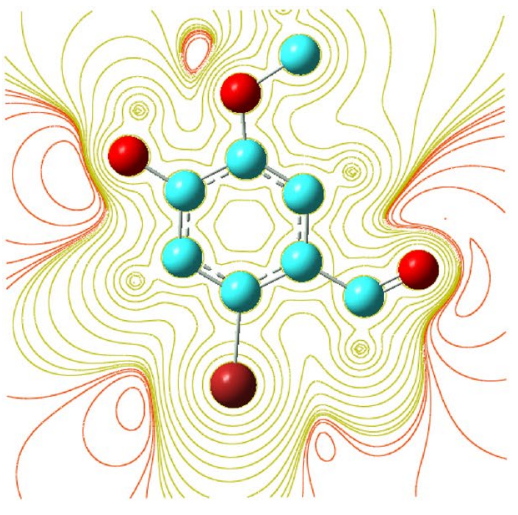

(a)

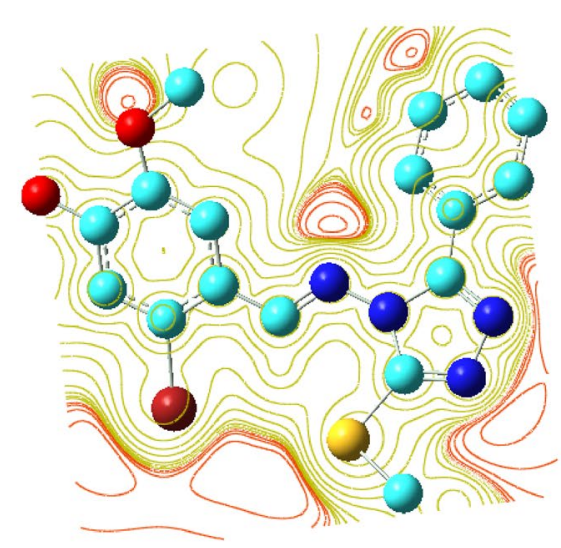

(b) 
Fig. 5 Equilibrium configurations of organic inhibitor molecules in solution. a 5-bromo4-formylguaiacol 1, b GO289 2
Fig. 6 Proposed complex structure and adsorption sites of GO289 2 in water on the iron surface

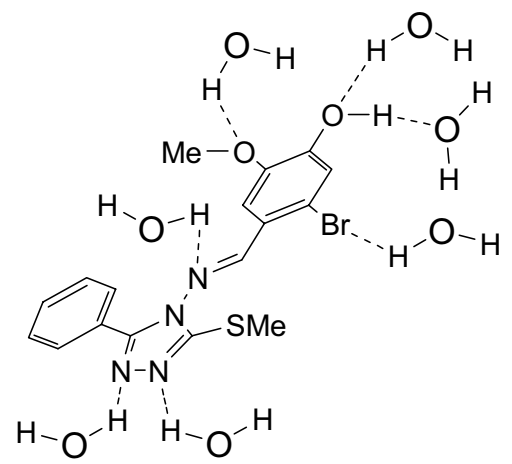

(a)

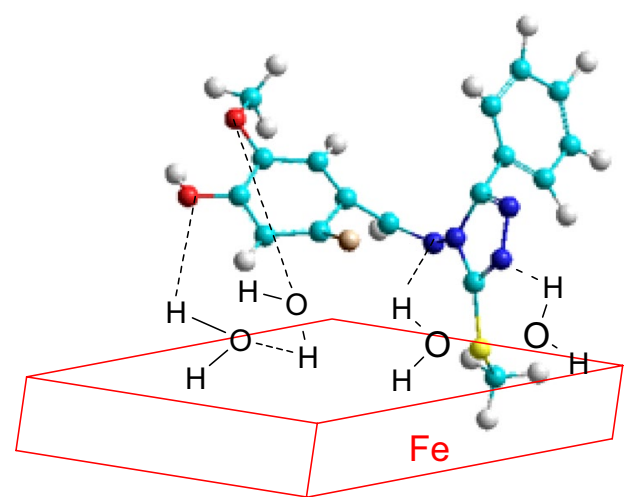

(b)

\section{Conclusion}

We have studied the reactivity of the GO289 2 and compound 1 using the DFT method. The results show that the electrophilicity index increases with various electrodificitary sites of GO289 2. We note that the fraction of electrons $\Delta N$ is large for GO289 2. Consequently, the inhibition is more efficient when using GO289 2 rather 5-bromo-4-formylguaiacol 1 . We have also evaluated the conformations of the GO289 2 and 1 using the molecular dynamics simulation in solution. We note that the 5-bromo-4-formylguaiacol 1 reaches it high planar conformation state in the solution environment. GO289 2 has a spatial and non-planar conformation and has the 
highest interaction energy because of multiple hydrogen bonds with water molecules. We confirm that the combination of the active structure of 1,2,4-triazole with that of substituted phenol has effectively increased the chemical properties and therefore the structure-activity relationship has been demonstrated.

We conclude that GO289 2 is a soft Schiff base with high chemical reactivity and strong tendency to adsorb on the metal surface. Our theoretical results complete very well the experimental data of literature.

\section{Compliance with ethical standards}

Conflict of interest There is no conflict of interest.

\section{References}

1. Freudenberg K (1965) Lignin: its constitution and formation from $p$-hydroxycinnamyl alcohols. Science 148:595-600

2. Lewis GN, Yamamoto E (1990) Lignin: occurrence, biogenesis and biodegradation. Annu Rev Plant Physiol Plant Mol Biol 41:455-496. https://doi.org/10.1146/annurev.pp.41.06019 0.002323

3. Takara K, Kinjyo A, Matsui D, Wada K, Nakason Y, Yogi S (2000) Antioxidative phenolic compounds from non-sugar fraction in Kokuto, non-centrifugal cane sugar. J Jpn Soc Biosci Biotech Agrochem. 74:885-890

4. Lynn DG, Chen RH, Manning KS, Wood HN (1987) The structural characterization of endogenous factors from Vinca rosea crown gall tumors that promote cell division of tobacco cells. Proc Natl Acad Sci USA 84:615-619. https://doi.org/10.1073/pnas.84.3.615

5. Okazaki M, Shuto Y (2001) Stereoselective synthesis of the neolignan, (+)-dehydrodiconiferyl alcohol. Biosci Biotechnol Biochem 65(5):1134-1140. https://doi.org/10.1271/bbb.65.1134

6. Mabic S, Lepoittevin J-P (1995) Regioselective bromination of O- $\beta$-glycosylated aromatics. Tetrahedron Lett 36:1705-1708. https://doi.org/10.1016/0040-4039(95)00050-M

7. Ogerhauser $T$ (1997) A new bromination method for phenols and anisoles: $\mathrm{nBS} / \mathrm{HBF}_{4}$. Et ${ }_{2} \mathrm{O}$ in $\mathrm{CH}_{3} \mathrm{CN}$. J Org Chem 62:45044506. https://doi.org/10.1021/jo9622993

8. Fujikawa N, Ohta T, Yamaguchi T, Fukuda T, Ishibashi F, Iwao M (2006) Total synthesis of lamellarins D, L, and N. Tetrahedron 62(4):594-604. https://doi.org/10.1016/j.tet.2005.10.014

9. Markina NA, Chen Y, Larock RC (2013) Efficient microwaveassisted one-pot three-component synthesis of 2,3-disubstituted benzofurans under Sonogashira conditions. Tetrahedron 69:2701-2713. https://doi.org/10.1016/j.tet.2013.02.003

10. Verma AM, Kishore N (2016) DFT analyses of reaction pathways and temperature effects on various guaiacol conversion reactions in gas phase environment. Chem Sel 1:6196-6205. https ://doi.org/10.1002/slct.201601139

11. Zhou M, Wang Y, Wang Y, Xiao G (2015) Catalytic conversion of guaiacol to alcohols for bio-oil upgrading. J Energy Chem 24:425-431. https://doi.org/10.1016/j.jechem.2015.06.012

12. Bykova MV, Zavarukhin SG, Trusov LI, Yakovlev VA (2013) Guaiacol hydrodeoxygenation kinetics with catalyst deactivation taken into consideration. Kinet Catal 54:40-48. https://doi. org/10.1134/S0023158413010023
13. Bui VN, Laurenti $D$, Delichère $P$, Geantet $C$ (2011) Hydrodeoxygenation of guaiacol: part II: Support effect for CoMoS catalysts on HDO activity and selectivity. Appl Catal B Environ 101:246255. https://doi.org/10.1016/j.apcatb.2010.10.031

14. Verma AM, Kishore N (2018) Molecular modeling approach to elucidate gas phase hydrodeoxygenation of guaiacol over a Pd catalyst within DFT framework. J Mol Model 24(9):254. https:// doi.org/10.1007/s00894-018-3803-8

15. Zhou M, Ye J, Liu P, Xu J, Jiang J (2017) Water-assisted selective hydrodeoxygenation of guaiacol to cyclohexanol over supported Ni and Co bimetallic catalysts, ACS Sustain. Chem Eng 5:8824-8835. https://doi.org/10.1021/acssuschemeng.7b01615

16. Agache C, Popa VI (2006) Ab Initio studies on the molecular conformation of lignin model compounds I. Conformational preferences of the phenolic hydroxyl and methoxy groups in guaiacol. Monatshefte Chem 137:55-68. https://doi.org/10.1007/s00706-005-0404-x

17. Agrawal K, Verma AM, Kishore N (2019) Thermochemical conversion of guaiacol in aqueous phase by density functional theory. Chem Sel 4:6013-6025. https://doi.org/10.1002/slct.201900437

18. Oshima T, Niwa Y, Kuwata K et al (2019) Cell-based screen identifies a new potent and highly selective CK2 inhibitor for modulation of circadian rhythms and cancer cell growth. Sci Adv 5:9060. https://doi.org/10.1126/sciadv.aau9060

19. Frisch MJ, Trucks GW, Schlegel HB et al (2004) Gaussian 03, Revision C.02, Gaussian, Inc., Wallingford CT

20. Becke AD (1993) Density-functional thermochemistry. III. The role of exact exchange. J Chem Phys. 98(7):5648-5652. https:// doi.org/10.1063/1.464913

21. Becke $A D$ (1988) Density-functional exchange-energy approximation with correct asymptotic behavior. Phys Rev A 38:30983100. https://doi.org/10.1103/PhysRevA.38.3098

22. Lee C, Yang W, Parr RG (1988) Development of the Colle-Salvetti correlation-energy formula into a functional of the electron density. Phys Rev B. 37:785-789. https://doi.org/10.1103/PhysR evB.37.785

23. Pearson RG (1989) Absolute electronegativity and hardness: applications to organic chemistry. J Org Chem 54:1423-1430. https://doi.org/10.1021/ja00171a007

24. Zhou Z, Parr RG (1990) Activation hardness: new index for describing the orientation of electrophilic aromatic substitution. J Am Chem Soc 112:5720-5724. https://doi.org/10.1021/ ja00171a007

25. Faust WL (1989) Explosive molecular ionic crystals. Science 245:37-42. https://doi.org/10.1126/science.245.4913.37

26. Maynard AT, Huang M, Rice WG, Covell DG (1998) Reactivity of the HIV-1 nucleocapsid protein p7 zinc finger domains from the perspective of density-functional theory. Proc Nat Acad Sci 95:11578-11583. https://doi.org/10.1073/pnas.95.20.11578

27. Parr RG, Szentpaly LV, Liu S (1999) Electrophilicity Index. J Am Chem Soc 121:1922-1924. https://doi.org/10.1021/ja983494x

28. Haque J, Srivastava V, Chauhan DS, Lgaz H, Quraishi MA (2018) Microwave-induced synthesis of chitosan Schiff bases and their application as novel and green corrosion inhibitors: experimental and theoretical approach. ACS Omega 3:5654-5668. https:// doi.org/10.1021/acsomega.8b00455

29. Kokalj A (2015) Ab initio modeling of the bonding of benzotriazole corrosion inhibitor to reduced and oxidized copper surfaces. Faraday Discuss 180:415-438. https://doi.org/10.1039/ c4fd00257a

30. Saha SK, Murmu M, Murmu NC, Banerjee P (2016) Evaluating electronic structure of quinazolinone and pyrimidinone molecules for its corrosion inhibition effectiveness on target specific mild steel in the acidic medium: a combined DFT 
and MD simulation study. J Mol Liq 224:629-638. https://doi. org/10.1016/j.molliq.2016.09.110

31. Zhang Z, Tian NC, Huang XD, Shang W, Wu L (2016) Synergistic inhibition of carbon steel corrosion in $0.5 \mathrm{M} \mathrm{HCl}$ solution by indigo carmine and some cationic organic compounds: experimental and theoretical studies. RSC Adv 6:22250-22268. https ://doi.org/10.1039/C5RA25359D

32. Murray S, Politzer P (2011) The electrostatic potential: an overview. Comput Mol Sci 2:153-163. https://doi.org/10.1002/ wcms.19

33. Messali M, Lgaz H, Dassanayake R, Salghi R, Jodeh S, Abidi N, Hamed $O$ (2017) Guar gum as efficient non-toxic inhibitor of carbon steel corrosion in phosphoric acid medium: electrochemical, surface, DFT and MD simulations studies. J Mol Struct 1145:43-54. https://doi.org/10.1016/j.molstruc.2017.05.081
34. Saha SK, Dutta A, Ghosh P, Sukul D, Banerjee P (2016) Novel Schiff-base molecules as efficient corrosion inhibitors for mild steel surface in $1 \mathrm{M} \mathrm{HCl}$ medium: experimental and theoretical approach. Phys Chem Chem Phys 18:17898-17911. https://doi. org/10.1039/C6CP01993E

35. Lgaz H, Salghi R, Bhat KS, Chaouiki A, Shubhalaxmi Jodeh $S$ (2017) Correlated experimental and theoretical study on inhibition behavior of novel quinoline derivatives for the corrosion of mild steel in hydrochloric acid solution. J Mol Liq 244:154-168. https://doi.org/10.1016/j.molliq.2017.08.121

36. Mahboub R (2020) Theoretical study of Schiff bases reactivity. Prediction of corrosion inhibition effect. Mol Simul 46(3):207212. https://doi.org/10.1080/08927022.2019.1690143

Publisher's Note Springer Nature remains neutral with regard to jurisdictional claims in published maps and institutional affiliations. 